\title{
Biofilm inhibition: the use of a marine alkaloid derivative in the prevention of clinically-relevant biofilms
}

\begin{abstract}
Biofilms are complex and highly resistant microbial communities of sessile cells, which are responsible for many human pathogeneses. Given the risk that biofilms present to public health, this study was performed to contribute to the body of knowledge in the area of infections control by investigating the ability of Agilyte ${ }^{\mathrm{TM}}$, a marine alkaloid derivative, to inhibit biofilms of clinical significance and a potential synergistic effect of Agilyte ${ }^{\mathrm{TM}}$ and Penicillin G. The bacteria methicillin-resistant Staphylococcus aureus (MRSA), Escherichia coli, Staphylococcus epidermidis, and Pseudomonas aeruginosa were used in an in-vitro study. Biofilms were established using microtiter plates incubating at $35^{\circ} \mathrm{C}$ for 24hours, under static and aerobic conditions. To evaluate biofilm inhibition properties and a combined synergistic effect, Agilyte ${ }^{\mathrm{TM}}$, with and without antibiotic, was added to bacterial cultures prior to incubation. Biofilm mass was determined using a crystal violet reporter assay and viable cells were determined using the drop-plate method. Independent samples t-test was used to compare biofilm mass from treated samples and positive controls. Statistical significance was set at $\mathrm{P}<0.05$. Mean $\log 10$ Reduction (LR) was calculated for viable plate counts and significant difference was set at $>0.3 \mathrm{LR}$.

The data collected provide evidence that Agilyte $^{\mathrm{TM}}$, at given concentrations and under specific biochemical environments, inhibit biofilms of both gram-positive and gramnegative bacteria. The data suggest that Agilyte ${ }^{\mathrm{TM}}$ may inhibit the AI-2 cell signaling mechanism in bacteria. This study did not provide conclusive evidence of a possible synergistic anti-biofouling/antimicrobial effect of Agilyte $^{\mathrm{TM}}$ and Penicillin G. However, given that the study yielded some questionable and variable results, data generated using polystyrene microtiter plates should be evaluated with caution and further studies are required to fully evaluate and validate the spectrum of anti-biofouling properties of this chemical compound. The biochemical environment where clinical bacterial biofilms form is an important factor when designing biofilm assays. Therefore, future in-vitrostudies should include accurate and representative models of relevant tissue and medical device surfaces where these microbial communities develop.
\end{abstract}

Keywords: staphylococcus aureus, microorganisms, biofilms, nosocomial infections, chemical concentration
Volume 6 Issue 5 - 2018

\author{
Lucia Clontz \\ A.T. Still University, Mesa, AZ, North Carolina State University, \\ Raleigh, NC, USA
}

Correspondence: Lucia Clontz, Quality Director, Xellia Pharmaceuticals, USA, Email: Lucia.Clontz@xellia.com

Received: June 30, 2018| Published: September 05, 2018
Abbrevations: EPS, extra polymeric substances; VNC, viable but not culturable; MRSA, methicillin-resistant Staphylococcus aureus; CV, crystal violet; LBNS, Luria bertani broth with no salt; $\mathrm{NIH}$, national institutes of health

\section{Introduction}

Biofilms are complex and three-dimensional communities of sessile cells encased in a slimy matrix of extra polymeric substances (EPS) and irreversibly attached to a surface. ${ }^{1}$ Biofilms are responsible for many human pathogeneses including chronic wounds, deviceassociated infections, and various nosocomial infections and diseases in patients with compromised immune systems. ${ }^{2}$ The predominance of biofilms in nature shows that microorganisms have a tendency to form complex microbial communities that are highly resistant to environmental stresses. Understanding how microorganisms develop into biofilm cells and the mechanisms of antimicrobial resistance present in biofilm communities are critical for the development of successful control of bacterial infections, which are a major concern in healthcare and often lead to higher rates of morbidity and mortality in patient populations. ${ }^{3}$ According to the U.S. National Institutes of Health $(\mathrm{NIH})$, approximately $80 \%$ of infections are due to microbial biofilms. ${ }^{4}$ Biofilms represent a public health risk due to four main reasons. First, it is accepted that microorganisms will develop into biofilms as long as moisture and a substratum are available. Second, when bacteria attach to a surface and develop into a biofilm, these microorganisms become more difficult to remove and kill when compared to planktonic cells or sessile cells that have not yet assumed a biofilm phenotype. Third, biofilm cells can be dispersed by processes such as shedding or by physical forces. Dispersed cells often retain their biofilm phenotype, including antimicrobial resistance and ability to attach to substrata, thus posing a risk of systemic infection. Lastly, biofilms shed toxins to include pyrogenic substances, such as endotoxins produced by gram-negative bacteria. ${ }^{5}$

Bacteria present in biofilms exhibit an altered phenotype in terms of growth rate and gene transcription. As a result, biofilm cells behave quite differently from their free-floating (planktonic) counterparts. This change in phenotype, combined with the metabolic cooperation among biofilm cells and the unique architecture of a biofilm community, leads to a multi-layer defense mechanism that results in an increased resistance to many chemicals and other types of environmental stresses that are lethal to planktonic cells. Biofilm infections are known for their refractory nature that requires repeated antibiotic treatments. ${ }^{6}$ 
In many cases, traditional culture methods used to sample wound sites were unable to recover contaminants, a fact that resulted in the erroneous assumption that chronic wounds were a sterile inflammatory condition. Further studies performed on cultures collected, using molecular biology and microscopic techniques, showed that viablebut-not-culturable (VNC) bacteria were present, metabolically active, and living in a matrix-enclosed community of cells. ${ }^{7}$ In a study where 50 chronic wound specimens were microscopically analyzed, $60 \%$ of the samples contained biofilms. Types of bacteria typically found on chronic wound sites are organisms from the genera Staphylococcus, Enterococcus, Pseudomonas, and the strictly anaerobes Prevotella and Porphorymonas. ${ }^{8}$

Biofilms are a major deterrent to the use of medical devices due to risk of infection. ${ }^{9}$ Device-related infections are difficult to treat using conventional antibiotics and they often prove fatal. The mortality rate for bloodstream infections associated with catheters is in the range of $12-25 \%{ }^{10}$ while mortality rate for prosthetic heart valve-related endocarditis is as high as $70 \%{ }^{6}$ The most common remediation for device-associated infections is removal of the contaminated implant. ${ }^{10}$ Over the years, many studies have been carried out in the areas of biofilm eradication, remediation, and prevention. However, the realization that biofilms are ubiquitous in nature and extremely difficult to destroy resulted in a shift in paradigm - from microbial eradication and remediation to biofilm prevention strategies. Since then, researchers have worked on novel approaches to create surfaces that prevent microbial adhesion and to develop compounds that prevent or disrupt biofilms. Despite the advances made in the area of biofilm prevention, few studies have been conducted to evaluate the synergistic antimicrobial effect of anti-biofouling compounds and antibiotics. This type of strategy could render bacterial pathogens, to include those that have developed antibiotic resistance, more susceptible to traditional antimicrobial therapies. ${ }^{10}$

Agilyte $^{\mathrm{TM}}$ (Agiles Sciences, Raleigh, NC) is a marine alkaloid derivative of the natural product bromoageliferin produced by reef sponges of the genus Agelas (Family Agelasidae). These organisms produce brominated pyrrole alkaloids, as secondary metabolites, for anti-predatory purposes. ${ }^{11}$ These chemicals also have the ability to prevent bacterial surface colonization by modulating biofilm formation. Previous studies using a similar bromoageliferin analogue demonstrated enhanced anti-biofilmproperties when used against the gram-positive bacterium Staphylococcus aureus and the gram-negative bacteria Pseudomonas aeruginosa and Acinetobacter baumannii. ${ }^{12}$ In addition; there was a lack of cytotoxicity detected when Agilyte ${ }^{\mathrm{TM}}$ was tested with mammalian cell lines. Given that Agilyte ${ }^{\mathrm{TM}}$ is able to maintain and/revert cells to their sensitive planktonic state and it is not cytotoxic, this chemical may act synergistically with conventional antibiotics and serve as an adjuvant for antimicrobial therapies. Agilyte $^{\mathrm{TM}}$ is a descriptive term for a family of about 500 non-toxic synthetic organic compounds, each having distinctive and selective abilities to disrupt and disperse bacterial biofilms. The chemical used in this study is Agilyte ${ }^{\mathrm{TM}} 8000$, one of a set of proposed leading antibiofilm candidates. ${ }^{13}$

The protocol used to grow biofilms in vitro was an adaptation of the microtiter plate methods described by Ren et al. ${ }^{14} \&$ Pitts et al. ${ }^{15}$ This test platform is a practical and relevant method to screen various chemical compounds against different types of microbial biofilms. The purpose of this study was to evaluate the ability of Agilyte ${ }^{\mathrm{TM}}$ to inhibit biofilms of clinically relevant bacteria. In addition, this study aimed to investigate a potential anti-biofouling synergistic effect between Agilyte ${ }^{\mathrm{TM}}$ and antibiotics approved to treat infections.

Selection of bacterial species was based on clinical relevance and their prevalence as isolates from infection sites. The study was conducted using two gram-negative bacteria (Pseudomonas aeruginosa and Escherichia coli) and two gram-positive bacteria (methicillinresistant Staphylococcus aureus [MRSA] and Staphylococcus epidermidis). The gram-negative bacterium Pseudomonas aeruginosa is an important causative agent of various types of acute and chronic infections that include wound infections at burn sites as well as infections associated with the respiratory system, otorrhea, cornea, and urinary tract system. In cystic fibrosis patients, this organism is the main cause of morbidity and mortality. ${ }^{16}$ Escherichia coli, a gram-negative enterobacterium, is often associated with urinary tract infections.${ }^{17}$ The gram-positive bacterium Staphylococcus epidermidis is a skin commensal and opportunistic pathogen that has become the leading cause of nosocomial and device-related infections. ${ }^{18}$ The grampositive bacterium Staphylococcus aureus is a common inhabitant of the human skin flora. This organism is considered a pathogen and it has been associated with many diseases and device-related infections that often lead to bacteremia. ${ }^{19}$ Given the increased number of cases of septicemia caused by MRSA, and the fact that this bacterium has become a major cause of mortality and morbidity in hospitalized patients ${ }^{2}$, MRSA was the Staphylococcus aureus type strain used in the study. The antibiotic chosen for the study, Penicillin G, is a commonly approved drug for the treatment of bacterial infections humans.

\section{Methods}

The chosen biofilm assay protocol was an adaptation of the microtiter plate methods described in the literature. ${ }^{14,15}$ Sterile tissue culture-treated 96-well polystyrene microtiter plates, with clear sides and clear bottoms and with a 300- $\mu$ l well capacity, were used for the study. To grow biofilms, a 200-microtiter $(\mu 1)$ aliquot of bacterial suspension was added to individual wells and plates incubated for 24 hours at $35^{\circ} \mathrm{C}$, under stationary and aerobic conditions. Following incubation, spent media and planktonic cells were removed and wells washed, four times, with sterile phosphate Butterfield's dilution buffer (PBS) to remove loose cells. Biofilms were then quantified using a crystal violet (CV) reporter assay, which uses absorbance (A540) values to represent biofilm mass. ${ }^{15}$ This was done by staining the sessile cells with $200 \mu$ l of Gram Crystal Violet (BD Diagnostics) for 10 minutes at ambient temperature $\left(18-25^{\circ} \mathrm{C}\right)$. Then, the excess stain was decanted and each well washed, four times, with $200 \mu 1$ of Purified Water (Milli-Q , Millipore Corporation). A 200- $\mu$ l aliquot of Gram decolorizer (BD Diagnostics) was added to each well and the plates incubated for 15 minutes at ambient temperature $\left(18-25^{\circ} \mathrm{C}\right)$. Blanks were prepared by staining sterile wells following the same procedure used for wells with biofilms. The solubilized stain preparations from each well (including blanks) were transferred into another sterile 96-well microtiter plate and absorbance measured at 540nm using a SpectraMax Plus spectrophotometer (Molecular Devices Inc., Sunnyvale, CA). Raw absorbance values from biofilm wells were corrected by subtracting from the mean blank value.

\section{Bacterial strains}

The following bacteria were used in the study: Escherichia coli (ATCC 8539), Staphylococcus epidermidis (ATCC 29886), methicillin-resistant Staphylococcus aureus, MRSA (ATCC BAA44), and Pseudomonas aeruginosa (PA14). 


\section{Media, materials, and reagents}

Bacteria were maintained on R2A medium (Difco) under refrigerated conditions $\left(2-8^{\circ} \mathrm{C}\right)$. Growth media used for the biofilm assays were $\mathrm{BBL}$ tryptic soy broth (TSB), Bacto ${ }^{\mathrm{TM}}$ tryptic soy medium with $0.3 \%$ glucose broth (TSBG), Luria-Bertani broth (LB), Lennox (BD Diagnostics), Luria-Bertani broth with no salt (LBNS), and M63 medium (1X of 5X stock solution [15g KH $\mathrm{KH}_{4}$, $35 \mathrm{~g} \mathrm{~K}_{2} \mathrm{HPO}_{4}, 10 \mathrm{~g}\left(\mathrm{NH}_{4}\right)^{2} \mathrm{SO}_{4}, 1 \mathrm{~L}$ water]) supplemented with $4 \%$ arginine (Sigma). Tryptic soy agar (TSA) and R2A medium (bio Merieux Clinical Diagnostics), and sterile phosphate Butterfield's dilution buffer (Remel) were used for plate count studies. Agilyte Тм 8000 stock solution was prepared at $1 \mathrm{mM}$ concentration in dimethyl sulfoxide (DMSO) and maintained under refrigerated conditions (2$8^{\circ} \mathrm{C}$ ). The studies were performed using concentrations of Agilyte ${ }^{\mathrm{TM}}$ ranging from $0.5 \mu \mathrm{M}$ to $500 \mu \mathrm{M}$. The antibiotic used for the synergistic effect studies was Penicillin G sodium salt (Sigma Aldrich, Catalog \# P3032).

\section{Study design}

This study was designed to determine the concentrations of Agilyte $^{\mathrm{TM}}$ that would inhibit biofilms of clinically relevant bacteria. The minimum biofilm inhibitory concentration (MBIC) values were determined and used to evaluate a potential anti-biofouling synergistic effect of Agilyte ${ }^{\mathrm{TM}}$ and Penicillin G. Biofilm Inhibition Determination. To study the anti-biofilm properties of Agilyte ${ }^{\mathrm{TM}}$, this chemical was added to an overnight bacterial culture adjusted to an optical density (OD) 600 of $0.01-0.03$. TSB and TSBG were used in studies with MRSA and $S$. epidermidis. TSB and LB were used in studies with E. coli. TSB, LB, LBNS, and M63 with arginine were used in studies with PA14. Various concentrations of Agilyte ${ }^{\mathrm{TM}}$ were evaluated to determine the MBIC for a given bacterial species. Bacterial suspensions without Agilyte $^{\mathrm{TM}}$ were treated as positive controls. A minimum of five replicates were prepared for each sample treatment and positive control. Biofilms were established in microtiter plate wells and quantified using a CV reporter assay, as described above. Percent biofilm inhibition was determined by comparing the mean absorbance value for biofilms formed in the presence of Agilyte $^{\mathrm{TM}}$ to the mean absorbance value for positive control biofilms.

\section{Determination of synergistic biofilm inhibition effect}

To study a potential synergistic anti-biofouling effect, Agilyte ${ }^{\mathrm{TM}}$ at the MBIC level and Penicillin G at a non-inhibitory concentration for a given species were added to overnight bacterial cultures, which had been adjusted to an OD600 of 0.01-0.03. TSBG and Penicillin G at $25 \mathrm{Mm}^{20}$ were used for studies with MRSA. TSBG and Penicillin G at $0.06 \mu \mathrm{M}^{21}$ were used with studies with $S$. epidermidis. Controls were prepared by growing biofilms in the presence of Penicillin G only and in the presence of Agilyte ${ }^{\mathrm{TM}}$ only. Positive controls were prepared by growing biofilms in the absence of both Agilyte ${ }^{\mathrm{TM}}$ and Penicillin G. A minimum of five replicates were prepared for each sample treatment and controls. Biofilms were established in microtiter plate wells and quantified using a CV reporter assay, as described above. Percent biofilm inhibition was determined by comparing the mean absorbance value for biofilms formed in the presence of Agilyte ${ }^{\mathrm{TM}}$, antibiotic, and Agilyte $^{\mathrm{TM}}$ with antibiotic to the mean absorbance value for positive control biofilms.

For some of the studies, viability of biofilm cells was determined using the drop plate method..$^{22}$ Following incubation at $35^{\circ} \mathrm{C}$ for 24-hours, under stationary and aerobic conditions, spent media and planktonic cells were removed and wells washed, four times, with sterile PBS to remove loose cells. Then, $200-\mu 1$ aliquots of sterile PBS were added to replicate wells, which were scraped with sterile plastic applicator sticks (Fischer Scientific Co., catalog \# 23-400-122) to dislodge the sessile cells. The buffer-cell suspension was aspirated and added to $4.6 \mathrm{ml}$ of sterile PBS contained in a test tube. Another 200- $\mu$ l aliquot of sterile PBS was added to the same wells, the scraping procedure repeated, and the buffer-cell suspension aspirated and added to the same test tube with sterile PBS for a final volume of $5 \mathrm{ml}$. The buffer-cell preparation was vortexed for 30 seconds and sonicated for 30seconds using the Aquasonic Model 50D sonicator (VWR Scientific, West Chester, PA). This procedure for biofilm disaggregation ${ }^{23}$ was repeated twice and the cell suspensions serially diluted and drop plated ${ }^{22}$ using R2A medium or TSA. Plates were incubated at $35^{\circ} \mathrm{C}$ for 17 to 20 hours. Following incubation, colonies recovered were enumerated using the Quebec colony counter (Reichert Analytical Instrument, Depew, NY). An appropriate dilution factor was used to determine the number of viable cells (biofilm mass) per well.

\section{Statistical analysis}

For experiments using the $\mathrm{CV}$ reporter assay, each raw absorbance value was corrected by subtracting the mean absorbance for blank wells prior to statistical analysis. For the biofilm inhibition method, an independent samples t-test was performed for comparisons of biofilm mass for the treated samples (mean of corrected absorbance values) and for the positive controls (mean of corrected absorbance values). Differences were considered significant for $p$ values of $<0.05$, twotailed. A measure of efficacy called Percent Biofilm Inhibition was calculated for treated samples that were statistically different from test controls. (Equation 1) Let A denote the corrected mean absorbance value for the positive control and B denote the corrected mean absorbance value for the treated sample.

\section{Percent Biofilm Inhibition $=(A-B) / A x 100$ [Eq. 1]}

For each set of experiments, the standard deviation (SD) of replicate measurements was also calculated to establish between-well variability. Then, the mean and $95 \%$ confidence intervals (CI) for the replicate Percent Biofilm Inhibition values were calculated. Data were reported as Percent Biofilm Inhibition \pm CI. All statistical analyses were performed using Microsoft ${ }^{\circledR}$ Excel 2007. For experiments to determine viability of biofilm cells, the number of colony forming units (viable cell density) was determined for replicate wells. Then, the average viable cell density was calculated and $\log 10$ transformed. Log reduction (LR) was calculated as the $\log 10$ density for treated wells subtracted from the $\log 10$ density for control wells. Differences were considered significant for LR values of $>0.3 .{ }^{24}$ Data were reported as Mean Biofilm Mass ( $\log 10$ CFU/well) and Log10 Reduction.

\section{Results}

\section{Effect of agilyte ${ }^{T M}$ on MRSA biofilm inhibition}

Agilyte $^{\mathrm{TM}}$ was tested for its impact on biofilm formation of MRSA (ATCC BAA-44) grown in TSB and TSBG media. Colorimetric assays of stained biofilm cells demonstrated that Agilyte ${ }^{\mathrm{TM}}$ prevents biofilm formation of MRSA growing at $35^{\circ} \mathrm{C}$ for 24 hours, under aerobic and static conditions. When MRSA was grown in TSB, biofilm inhibition was variable and there was no statistically significant difference $(p>0.05)$ between biofilm mass formed in the presence and absence 
of Agilyte ${ }^{\mathrm{TM}}$. However, statistically significant changes in bacterial behavior were observed $(\mathrm{p}<0.05)$ when MRSA was grown in TSBG. After a 24-hour incubation period, Agilyte ${ }^{\mathrm{TM}}$ at various concentrations inhibited biofilm formation. Mean biofilm inhibition values for ten replicate samples (two separate experiments of five replicates each) treated with Agilyte ${ }^{\mathrm{TM}}$ at concentrations of $100 \mu \mathrm{M}, 150 \mu \mathrm{M}$, and $200 \mu \mathrm{M}$ were $37.9 \%, 92.6 \%$, and $80.3 \%$, respectively (Table 1 ).
Results obtained with Agilyte ${ }^{\mathrm{TM}}$ tested at concentrations lower than $200 \mu \mathrm{M}$ were more variable and for many experiments, there was no statistically significant difference $(p>0.05)$ between samples treated with Agilyte ${ }^{\mathrm{TM}}$ and test controls (Table 1). Therefore, Agilyte ${ }^{\mathrm{TM}}$ at $200 \mu \mathrm{M}$ was selected as the MBIC and used in studies to evaluate the synergistic effect of Agilyte ${ }^{\mathrm{TM}}$ and Penicillin G against MRSA.

Table I Test Results for MRSA-Mean Percent Biofilm Inhibition in the Presence of Agilyte ${ }^{\text {TM }}$

\begin{tabular}{lllllllllll}
\hline \multicolumn{10}{c}{ Agilyte $^{\mathrm{TM}}$ Concentration $(\boldsymbol{\mu M})$} \\
\hline Experiment & No. Replicates & $\mathbf{5 0}$ & $\mathbf{6 0}$ & $\mathbf{8 0}$ & $\mathbf{1 0 0}$ & $\mathbf{1 2 0}$ & $\mathbf{1 5 0}$ & $\mathbf{2 0 0}$ & $\begin{array}{c}\text { Growth } \\
\text { medium }\end{array}$ \\
\hline 1 & 5 & & $\mathrm{NC}$ & $\mathrm{NCN}$ & $\mathrm{CNC}$ & - & - & $\mathrm{TSB}$ & \\
2 & 5 & - & - & - & $\mathrm{NC}$ & $\mathrm{NCN}$ & $\mathrm{CNC}$ & $\mathrm{TSB}$ & \\
3 & 5 & - & - & 64.6 & 63.2 & - & 73.6 & 78.3 & $\mathrm{TSBG}$ \\
4 & 5 & - & - & $\mathrm{NC}$ & 12.6 & - & 111.6 & - & $\mathrm{TSBG}$ \\
5 & 5 & 29.5 & - & $\mathrm{NC}$ & $\mathrm{NC}$ & - & $\mathrm{NC}$ & 82.2 & $\mathrm{TSBG}$ \\
\hline Mean CI & & & & & 37.9 & & 93 & 80.3 & \\
& & & & & & \pm & & \pm 26.3 & \pm 2.7 & \\
\hline
\end{tabular}

\section{Synergistic effect of agilyte ${ }^{\mathrm{TM}}$ and penicillin $\mathbf{G}$ on MRSA biofilm inhibition}

To study the synergistic effect of Agilyte ${ }^{\mathrm{TM}}$ and Penicillin $\mathrm{G}$ on biofilm formation, MRSA (ATCC BAA-44) was grown in TSBG at $35^{\circ} \mathrm{C}$ for 24 hours, under aerobic and static conditions, and in the presence of Agilyte ${ }^{\mathrm{TM}}$ at $200 \mu \mathrm{M}$ and Penicillin $\mathrm{G}$ at $25 \mu \mathrm{M}$ (maximum non-inhibitory concentration). Colorimetric assays of stained biofilm cells from 12 replicate samples demonstrated a potential synergistic biofilm inhibition effect of Agilyte $^{\mathrm{TM}}$ and Penicillin $\mathrm{G}$ under the given test conditions. As expected, when MRSA was grown in the presence of $25 \mu \mathrm{M}$ Penicillin $\mathrm{G}$ only, there was no statistically significant difference $(p=0.67)$ between biofilm mass from treated samples and test positive controls (biofilms grown in TSBG only). When MRSA was grown in the presence of $200 \mu \mathrm{M}$ Agilyte ${ }^{\mathrm{TM}}$ only, unexpectedly, no statistically significant difference $(\mathrm{p}=0.73)$ between biofilm mass from treated samples and test positive controls was detected. However, for the wells that contained both $200 \mu \mathrm{M}$ Agilyte ${ }^{\mathrm{TM}}$ and $25 \mu \mathrm{M}$ Penicillin $\mathrm{G}$, biofilm formation was inhibited by $54.4 \%$ ( $\mathrm{p}=$ 0.02 ). Due to the variability in assay results for this experiment, this test is considered inconclusive since biofilm inhibition could have been due solely to the presence of Agilyte ${ }^{\mathrm{TM}}$ in the test sample.

Note. Dashes indicate chemical concentration not tested. $\mathrm{NC}=\mathrm{no}$ changes in biofilm mass when compared to controls $(p>0.05)$.

For comparative purposes, viable plate counts were performed. For each replicate testing, three wells from each sample treatment were selected. Biofilm mass collected was serial diluted in PBS and plated with R2A medium. Test plates incubated at $35^{\circ} \mathrm{C}$ for $16-20$ hours. For Replicate 1, plate count results did not show changes in viability of biofilm cells for treated and untreated samples. Serial dilutions for Replicate 2 samples were refrigerated $\left(2-8^{\circ} \mathrm{C}\right)$ for 18 hours prior to plating. As expected, there was no viability loss for biofilm cells from test positive control and Agilyte ${ }^{\mathrm{TM}}$ sample preparations. However, refrigeration resulted in loss of viability for biofilm cells in the presence of $25 \mu \mathrm{M}$ Penicillin $\mathrm{G}(1.3 \log 10$ reduction) and a potential antimicrobial synergistic effect $(1.9 \log 10$ reduction) between $200 \mu \mathrm{M}$ Agilyte $^{\mathrm{TM}}$ and $25 \mu \mathrm{M}$ Penicillin $\mathrm{G}$ (Table 2).The 0.6 difference in log reduction between samples treated with Penicillin $G$ and samples treated with Penicillin $\mathrm{G}$ and Agilyte ${ }^{\mathrm{TM}}$ can be considered greater than normal variability in microbial count (i.e., $>0.3 \log$ ), and therefore a possible indication of enhanced biofilm inhibition effect.

Table 2 Synergistic Inhibition Effect of Agilyte ${ }^{\mathrm{TM}}$ and Penicillin $\mathrm{G}$ on MRSA Biofilms - Viability Study

\begin{tabular}{|c|c|c|c|}
\hline Sample & $\begin{array}{l}\text { Mean } \\
\text { Biofilm } \\
\text { Mass (log } 10 \\
\text { CFU/well) }\end{array}$ & $\begin{array}{l}\text { Mean } \\
\text { Biofilm } \\
\text { Mass'(log 10 } \\
\text { CFU/well) }\end{array}$ & $\log _{10}$ Variabilityc \\
\hline Positive control & 6.3 & 6.4 & - \\
\hline Agilyte $^{\mathrm{TM}}(200 \mu \mathrm{M})$ & 6.7 & 6.6 & +0.2 \\
\hline Penicillin G $(25 \mu \mathrm{M})$ & 6.5 & 5.1 & -1.3 \\
\hline Agilyte $^{\mathrm{TM}}(200 \mu \mathrm{M}) /$ & 6.5 & 4.5 & -1.9 \\
\hline
\end{tabular}

Note. $\mathrm{CFU}=$ colony forming unit. Mean results based on triplicate samples. Dash indicates data not applicable

a. Sample serial dilutions not refrigerated.

b. Sample serial dilutions refrigerated for 18 hours prior to plating with R2A medium.

c. Log variability of refrigerated treated samples compared to refrigerated positive control

\section{Effect of agilyte ${ }^{\mathrm{TM}}$ on S. epidermidis biofilm inhibition}


Agilyte $^{\mathrm{TM}}$ was tested for its impact on biofilm formation of $S$. epidermidis (ATCC 29886) grown in TSB and TSBG. Colorimetric assays of stained biofilm cells demonstrated that Agilyte ${ }^{\mathrm{TM}}$ inhibits biofilm formation of $S$. epidermidis growing at $35^{\circ} \mathrm{C}$ for 24 hours, under aerobic and static conditions. Biofilm inhibition was similar but slightly greater in TSB when compared to TSBG. Mean Biofilm inhibition values for five replicate samples in TSB treated with Agilyte $^{\mathrm{TM}}$ at concentrations of $80 \mu \mathrm{M}, 100 \mu \mathrm{M}$, and $120 \mu \mathrm{M}$ were $84.5 \%, 89.7 \%$, and $87.6 \%$, respectively (Table 3). Mean biofilm inhibition values for 10 replicate samples (two separate experiments of five replicates each) treated with Agilyte ${ }^{\mathrm{TM}}$ at concentrations of $80 \mu \mathrm{M}$ and $100 \mu \mathrm{M}$ were $74.3 \%$ and $78.3 \%$, respectively (Table 3 ). The biofilm inhibition value based on five replicate samples treated with Agilyte $^{\mathrm{TM}}$ at a concentration of $150 \mu \mathrm{M}$ in TSBG was $70.3 \%$. Some replicate results obtained with Agilyte ${ }^{\mathrm{TM}}$ tested at concentrations equal to $60 \mu \mathrm{M}$ in $\mathrm{TSB}$, and $150 \mu \mathrm{M}$ and $200 \mu \mathrm{M}$ in TSBG were not statistically significant different $(p>0.05)$ from test positive controls. Based on data collected, Agilyte ${ }^{\mathrm{TM}}$ at $100 \mu \mathrm{M}$ was selected as the MBIC and used in studies to evaluate the synergistic effect of Agilyte $^{\mathrm{TM}}$ and Penicillin G against S. epidermidis.

Note. Dashes indicate chemical concentration not tested. $\mathrm{NC}=$ no changes in biofilm mass when compared to controls $(p>0.05)$.

Table 3 Test Results for S. epidermidis - Mean Percent Biofilm Inhibition in Agilyte ${ }^{\mathrm{TM}}$

\begin{tabular}{|c|c|c|c|c|c|c|c|c|}
\hline \multirow[b]{2}{*}{ Experiment } & \multirow[b]{2}{*}{ No. Replicates } & \multirow[b]{2}{*}{60} & \multicolumn{3}{|c|}{ 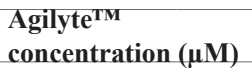 } & \multirow[b]{2}{*}{150} & \multirow[b]{2}{*}{200} & \multirow[b]{2}{*}{$\begin{array}{l}\text { Growth } \\
\text { Medium }\end{array}$} \\
\hline & & & 80 & 100 & 120 & & & \\
\hline 1 & 5 & $\mathrm{NC}$ & 84.5 & 89.7 & 87.6 & - & - & TSB \\
\hline 2 & 5 & - & 50.5 & 50.5 & - & $\mathrm{NC}$ & $\mathrm{NC}$ & TSBG \\
\hline 3 & 5 & - & 87.8 & 94.6 & - & 70.3 & - & TSBG \\
\hline Mean (TSBG only) & 69.2 & 72.6 & & & & & & \\
\hline $\begin{array}{l}\text { Mean (TSBG and } \\
\text { TSB) }\end{array}$ & 74.3 & 78.3 & & & & & & \\
\hline CI (TSBG/TSB) & \pm 23.3 & \pm 27.4 & & & & & & \\
\hline
\end{tabular}

Synergistic effect of agilyte ${ }^{\mathrm{TM}}$ and penicillin $\mathbf{G}$ on $\mathbf{S}$. epidermidis biofilm inhibition

To study the synergistic effect of Agilyte ${ }^{\mathrm{TM}}$ and Penicillin $\mathrm{G}$ on biofilm formation, S. epidermidis (ATCC 29886) was grown in TSBG at $35^{\circ} \mathrm{C}$ for 24 hours, under aerobic and static conditions, and in the presence of $100 \mu \mathrm{M}$ Agilyte $^{\mathrm{TM}}$ and $0.06 \mu \mathrm{M}$ Penicillin G (maximum non-inhibitory concentration). Colorimetric assays of stained biofilm cells from 12 replicate samples did not show a synergistic effect of Agilyte $^{\mathrm{TM}}$ and Penicillin G.As expected, mean colorimetric assay values of stained biofilm cells showed no statistically significant difference $(p=0.69)$ between biofilm mass formed in the presence of $0.06 \mu \mathrm{M}$ Penicillin $\mathrm{G}$ and biofilm mass from the test positive control. Also as expected, a mean $65.5 \%$ biofilm inhibition in the presence of $100 \mu \mathrm{M}$ Agilyte ${ }^{\mathrm{TM}}(\mathrm{p}<0.001)$ was observed. In addition, in the presence of both $100 \mu \mathrm{M}$ Agilyte ${ }^{\mathrm{TM}}$ and $0.06 \mu \mathrm{M}$ Penicillin G (p < 0.001 ) a mean $64.4 \%$ biofilm inhibition was observed. No additional biofilm inhibition was evident as a result of a possible synergistic effect between Agilyte ${ }^{\mathrm{TM}}$ and Penicillin $\mathrm{G}$ at the concentrations tested. Figure 1 shows a summary of results obtained. No viable plate counts were performed for comparative purposes.

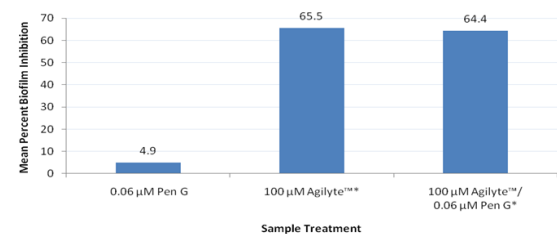

Figure I Synergistic inhibition effect of Agilyte ${ }^{\mathrm{TM}}$ and Penicillin G on S. epidermidis biofilms. Treated samples compared to test positive controls. Mean percent biofilm inhibition based on 12 replicate samples. Note. ${ }^{*} p<0.001$. Effect of agilyte ${ }^{T M}$ on E. coli biofilm inhibition

Agilyte $^{\mathrm{TM}}$ was tested for its impact on biofilm formation of $E$. coli (ATCC 8739) grown in TSB and LB media. Colorimetric assays of stained biofilm cells were used to quantify biofilm mass. Two separate experiments performed showed that when E. coli was grown in $\mathrm{TSB}$ at $35^{\circ} \mathrm{C}$ for 24 hours, under aerobic and static conditions, biofilm growth increased with increased concentration of Agilyte ${ }^{\mathrm{TM}}$ (Figure 2). However, when E. coli was grown in $\mathrm{LB}$ at $35^{\circ} \mathrm{C}$ for 24 hours, under aerobic and static conditions, biofilm mass decreased as concentration of Agilyte ${ }^{\mathrm{TM}}$ increased (Figure 3). Mean percent E. coli biofilm inhibition values for five replicate samples treated with Agilyte ${ }^{\mathrm{TM}}$ were as follows: $30 \mu \mathrm{M}(37.8 \%, \mathrm{p}=0.04), 50 \mu \mathrm{M}(61.2 \%$, $\mathrm{p}<0.001), 80 \mu \mathrm{M}(86.6 \%, \mathrm{p}=0.15 ; 63.8 \%, \mathrm{p}=<0.001), 100 \mu \mathrm{M}$ $(85.3 \%, \mathrm{p}=0.15 ; 87.2 \%, \mathrm{p}=<0.001), 150 \mu \mathrm{M}(84.9 \%, \mathrm{p}=0.15)$, and $200 \mu \mathrm{M}(75.6 \%, \mathrm{p}=0.20 ; 79.3 \%, \mathrm{p}=<0.001)$

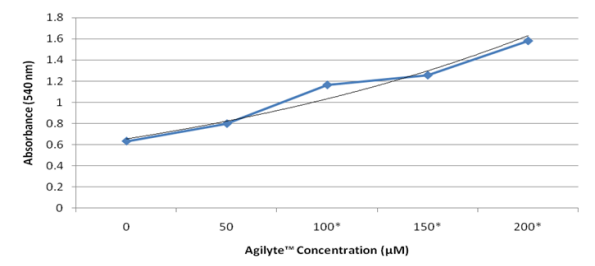

Figure 2 Effect of Agilyte ${ }^{\mathrm{TM}}$ on E. coli biofilms grown in TSB at $35^{\circ} \mathrm{C}$ for 24hours. Experiment 2. Mean absorbance values based on five replicate samples. Note. ${ }^{\mathrm{p}}<0.05$.

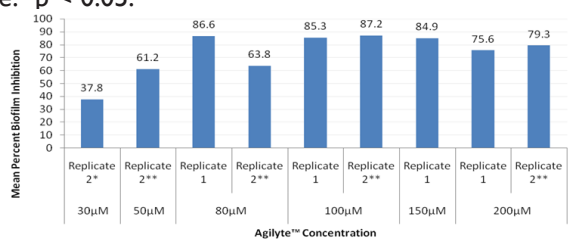

Figure 3 Effect of Agilyte ${ }^{\mathrm{TM}}$ on inhibition of E. coli biofilms grown in LB at $35^{\circ} \mathrm{C}$ for 24 hours. Mean results based on five replicate samples. Treated samples compared to test positive controls. Note. ${ }^{*} \mathrm{p}<0.05$, $* * \mathrm{p}<0.001$. 


\section{Effect of agilyte ${ }^{\mathrm{TM}}$ on pseudomonas aeruginosa biofilm inhibition}

Agilyte $^{\mathrm{TM}}$ was tested for its impact on biofilm formation of $P$. aeruginosa (PA14) grown in various types of media including TSB, LB, LBNS, and M63 with arginine. Colorimetric assays of stained biofilm cells were used to quantify biofilm mass. When PA14 was grown in TSB medium at $35^{\circ} \mathrm{C}$ for 24 hours, under aerobic and static conditions, Agilyte ${ }^{\mathrm{TM}}$ at the concentrations tested enhanced biofilm formation (Figure 4). A similar bacterial behavior was observed when PA14 was added to LB medium spiked with Agilyte ${ }^{\mathrm{TM}}$ and allowed to grow at $35^{\circ} \mathrm{C}$ for 24 hours, under aerobic and static conditions. However, although biofilm enhancement was observed across a wide chemical concentration range $(0.5 \mu \mathrm{M}$ to $500 \mu \mathrm{M})$, at low $(0.5 \mu \mathrm{M}, 5 \mu \mathrm{M}$, and $10 \mu \mathrm{M})$ and high $(500 \mu \mathrm{M})$ concentrations, biofilm formation was more pronounced as compared to biofilms formed for samples treated with $50 \mu \mathrm{M}, 100 \mu \mathrm{M}$, and $200 \mu \mathrm{M}$ of Agilyte ${ }^{\mathrm{TM}}$ (Figure 5) (Table 4). Bacterial behavior in LBNS treated with Agilyte ${ }^{\mathrm{TM}}$ was variable and inconsistent. For example, in one study, $100 \mu \mathrm{M}$ of Agilyte $^{\mathrm{TM}}$ yielded a $26.4 \%(\mathrm{p}=0.03)$ mean biofilm inhibition while in a replicate study, the same concentration of Agilyte ${ }^{\mathrm{TM}}$ led to a $67.2 \%$ $(\mathrm{p}<0.001)$ mean increase in biofilm formation (Figure 6). Percent values were calculated in comparison to test positive controls.

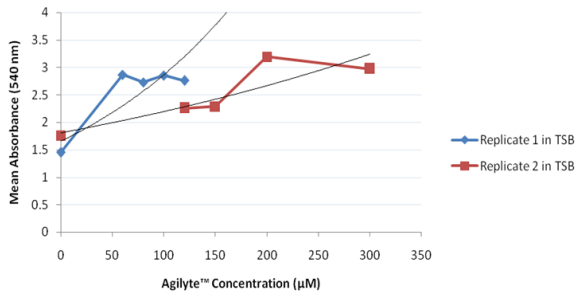

Figure 4 Effect of Agilyte ${ }^{\mathrm{TM}}$ on PAI4 biofilms grown in TSB at $35^{\circ} \mathrm{C}$ for 24 hours. Mean absorbance based on five replicate samples.

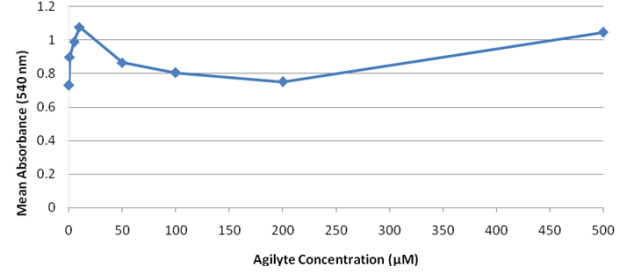

Figure 5 Effect of Agilyte ${ }^{\mathrm{TM}}$ on PAI4 biofilms grown in LB at $35^{\circ} \mathrm{C}$ for 24 hours. Mean absorbance based on seven replicate samples.

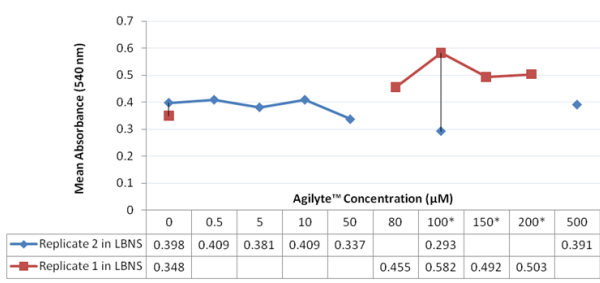

Figure 6 Effect of Agilyte ${ }^{\mathrm{TM}}$ on PA I 4 biofilms grown in LBNS. Mean absorbance values for Replicate I study based on five replicate samples. Mean absorbance values for Replicate 2 study based on six replicate samples. Note. ${ }^{*} \mathrm{p}<0.05$.

A low-nutrient medium, M63 with arginine, was then used to grow PA14 biofilms. Following a 24-hour incubation period at $35^{\circ} \mathrm{C}$, under aerobic and static conditions, there was no turbidity in the medium contained in the inoculated wells. Under similar incubation conditions,
PA14 preparations in TSB, LB, and LBNS media produced turbidity with planktonic, sessile cells, and pellicle formation. To increase biofilm mass for optimum quantitation, microtiter plates with PA14 in M63 medium with arginine continued incubation for a total of six days. Then, plates were removed from the incubator and observed for biofilm formation. There was still little to no visual turbidity as a result of planktonic cell growth. However, biofilms were present on the side and bottom of the wells.

Colorimetric assays of stained biofilm cells demonstrated that Agilyte ${ }^{\mathrm{TM}}$ prevents biofilm formation of PA14 grown in M63 medium with arginine. However, there was no direct correlation between biofilm inhibition and concentration of Agilyte ${ }^{\mathrm{TM}}$. For samples treated with $0.5 \mu \mathrm{M}, 5 \mu \mathrm{M}, 10 \mu \mathrm{M}$, and $500 \mu \mathrm{M}$ of Agilyte ${ }^{\mathrm{TM}}$, mean biofilm inhibition, in comparison to test positive controls, was 31.2\% (p< $0.001), 29.4 \%(\mathrm{p}<0.01), 47.0 \%(\mathrm{p}<0.001)$, and $86.0 \%(\mathrm{p}<0.001)$, respectively. For samples treated with $50 \mu \mathrm{M}$ of Agilyte ${ }^{\mathrm{TM}}$, there was no statistically significant difference between biofilm mass for treated samples and test positive controls $(\mathrm{p}=0.07)$ and for samples treated with $100 \mu \mathrm{M}$ and $200 \mu \mathrm{M}$ of Agilyte ${ }^{\mathrm{TM}}$, biofilm mass increased, in comparison to test positive controls, by $16.3 \%(\mathrm{p}=0.04)$ and $64.7 \%$ $(\mathrm{p}<0.001)$, respectively (Figure 7).

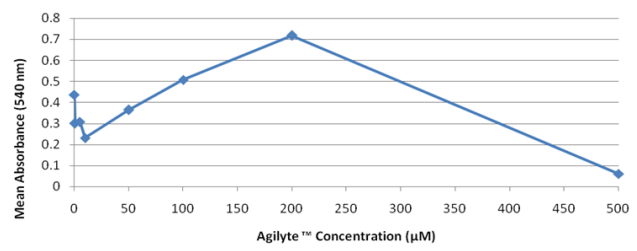

Figure 7 Effect of Agilyte ${ }^{\mathrm{TM}}$ on PAI4 biofilms grown in M63 medium with arginine for 6 days at $35^{\circ} \mathrm{C}$. Mean absorbance based on six replicate samples.

\section{Discussion}

In this study, we examined the effect of Agilyte ${ }^{\mathrm{TM}}$ on inhibiting biofilms of clinically relevant bacteria. Our findings provide evidence that Agilyte ${ }^{\mathrm{TM}}$ can prevent biofilm formation of MRSA, E. coli, $S$. epidermidis, and $P$. aeruginosa (PA14) under specific conditions. However, data collected were variable and confirmed that bacterial behavior and biofilm formation are dependent on available nutrients and environmental conditions. Therefore, anti-biofilm activity appears to be dependent on bacterial behavior in specific biochemical environments rather than a generic phenomenon correlated to concentrations of a given chemical, such as Agilyte ${ }^{\mathrm{TM}}$. In addition, Agilyte $^{\mathrm{TM}}$ showed variable and, sometimes, agonistic effects on biofilm formation when high nutrient media were used to grow grampositive and gram-negative bacteria. For example, Agilyte ${ }^{\mathrm{TM}}$ inhibited MRSA biofilms grown in TSBG and $S$. epidermidis biofilms grown in TSB and TSBG but enhanced E. coli and PA14 biofilms grown in TSB. Agilyte ${ }^{\mathrm{TM}}$ also inhibited E. coli biofilms but not PA14 biofilms, both grown in LB medium. Our data showed that Agilyte ${ }^{\mathrm{TM}}$ only inhibited PA14 biofilms grown in a very-low nutrient medium (M63) supplemented with arginine.

Colorimetric assays could not provide conclusive evidence of a combined synergistic inhibitory effect of $200 \mu \mathrm{M}$ Agilyte ${ }^{\mathrm{TM}}$ and $25 \mu \mathrm{M}$ Penicillin G on MRSA biofilms. Despite a difference in biofilm mass determined using a $\mathrm{CV}$ reporter assay, plate counts did not show a difference in cell viability between treated samples and positive controls, and between biofilms treated with Penicillin G only and 
those treated with both Agilyte ${ }^{\mathrm{TM}}$ and Penicillin G. These data show that biofilm mass determined by colorimetric methods does not always correlate with cell viability. A duplicate set of dilutions with biofilm cells recovered from the microtiter plate wells was refrigerated (2$8^{\circ} \mathrm{C}$ ) for 18 hours prior to plating with R2A medium. As expected, there were no changes in count (within $0.3 \mathrm{log}$ ) for the positive control and samples treated with Agilyte ${ }^{\mathrm{TM}}$, thus confirming the stability of microbial populations under short-term refrigeration. However, cell viability in the presence of $25 \mu \mathrm{M}$ of Penicillin $\mathrm{G}$ and in the presence of both $25 \mu \mathrm{M}$ of Penicillin $\mathrm{G}$ and $200 \mu \mathrm{M}$ Agilyte $^{\mathrm{TM}}$ was reduced by $1.3 \log 10$ and $1.9 \log 10$, respectively. These data show not only increased antibiotic activity, due to a slowdown in cell metabolism, but also a synergistic antimicrobial effect between Agilyte ${ }^{\mathrm{TM}}$ and Penicillin G under cold conditions. Thus, these results open the possibility of using Agilyte ${ }^{\mathrm{TM}}$ as an adjuvant for topical antimicrobial therapies (e.g., skin wounds) used in combination with cold therapies, which already have proven benefits in reducing inflammation. No synergistic biofilm inhibition effect of Agilyte ${ }^{\mathrm{TM}}$ and Penicillin G, at the concentrations tested, was observed for $S$. epidermidis. A mean $65.5 \%$ biofilm inhibition in the presence of $100 \mu \mathrm{M}$ Agilyte $^{\mathrm{TM}}$ was observed in comparison to a mean $64.4 \%$ inhibition for biofilms treated with both $100 \mu \mathrm{M}$ Agilyte ${ }^{\mathrm{TM}}$ and $0.06 \mu \mathrm{M}$ Penicillin G. It is worth noting that this experiment was conducted using TSBG and not $\mathrm{TSB}$, which yielded a greater biofilm inhibitory effect when tested with Agilyte ${ }^{\mathrm{TM}}$ alone. Perhaps results would have been different using an alternate growth medium.

Quorum sensing (QS) plays a key role in the initial stages of biofilm formation and in biofilm dispersion. This phenomenon is a type of cell to cell signaling mechanism that enables a bacterium to regulate gene expression in response to cell population density and facilitates an organism's adaptation to changing environmental conditions. QS depends on the production of small diffusible signal molecules called auto inducers (AI) that fall into three chemical families: acylated homoserine lactones (AI-1) found in gram-negative bacteria, oligopeptides found in gram-positive bacteria, and a system designated AI-2 that is mediated by a highly conserved gene (luxS) and is used by both gram-negative and gram-positive bacteria. Besides QS, AI-2 controls many other bacterial traits and its target receptor is species-dependent. Because of its unique characteristics, $\mathrm{AI}-2$ is believed to be an interspecies communication system. ${ }^{25}$

Given that Agilyte ${ }^{\mathrm{TM}}$ affects biofilm formation of both grampositive and gram-negative bacteria, it is hypothesized that Agilyte ${ }^{\mathrm{TM}}$ might play a role in regulating the AI-2 cell signaling mechanism. Furanone compounds, also derived from marine organisms, are known to interfere with the AI-2 bacterial communication system. ${ }^{26}$ This hypothesis may be supported by significant differences in the effect that Agilyte ${ }^{\mathrm{TM}}$ has on biofilm formation for gram-negative and gram-positive bacteria growing in TSB and TSBG, which contain glucose. Studies have provided evidence that AI-2 is produced in the presence of preferred carbohydrates and metabolized when primary nutrients are depleted ${ }^{27}$ and that AI-2 uptake is necessary for biofilm formation ${ }^{28}$ Among carbohydrates that can be metabolized, glucose is preferred by many bacteria including Staphylococcus spp. ${ }^{29}$ Therefore, it is expected that in TSB/TSBG, S. epidermidis and MRSA would produce and internalize AI-2 as the primary cell signaling mechanism. Data collected suggest that MRSA may require a higher concentration of glucose, which is present in TSBG when compared to TSB to utilize the AI-2 as the main cell-to-cell signaling mechanism. E. coli grown in LB medium releases and accumulates AI-2. However, when E. coli is grown in the presence of glucose, AI-2 cannot be internalized, due to catabolite repression, and accumulates in the medium. ${ }^{30}$ Therefore, it is suggested that in LB medium, $E$. coli uses AI-2 as a cell signaling system for biofilm formation but in $\mathrm{TSB}$, the primary AI-1 system is used. The hypothesis that Agilyte ${ }^{\mathrm{TM}}$ regulates the AI-2 cell signaling system explains why this chemical inhibited biofilm formation of $S$. epidermidis and MRSA growing in TSB/TSBG and of $E$. coli growing in LB but could not inhibit biofilm formation of E. coli growing in TSB. Pseudomonas aeruginosa uses the two major and distinct QS regulatory systems (lasR-I and rhIR-I), which work in concert and are controlled via a hierarchal process.$^{31}$ In addition, this bacterium has a separate cell signaling system called the Pseudomonas quinolone signal, which is induced by lasR-I and which induces the RhlR-I system. P. aeruginosa does not contain the luxS gene or generate AI-2 signaling molecules. It does, however, express the receptor complex of the AI-2 two-component QS system. Given that $P$. aeruginosa does not produce AI-2, the lack of biofilm inhibition when PA14 was cultured in TSB, LB, and LBNS could be explained by the hypothesis that Agilyte ${ }^{\mathrm{TM}}$ regulates the AI- 2 cell signaling system. However, Agilyte ${ }^{\mathrm{TM}}$ successfully inhibited PA14 biofilm formation, at certain concentrations, when this bacterium was grown in low-nutrient medium using arginine as the sole nitrogen and carbon source. To explain this result, two hypotheses are proposed. First, it is possible that PA14, in a low-nutrient chemical environment, produces a QS cell signaling molecule, homologous to the one from the AI-2cell signaling system, which is detected by the AI- 2 receptor. Thus, it is possible that PA14 uses the AI-2 system not only to detect signals from other bacterial populations but also as an alternative cell signaling detector that is part of its complex QS system. If this hypothesis holds true, it is possible that Agilyte ${ }^{\mathrm{TM}}$ inhibits biofilm formation by blocking the AI-2 receptor rather than down regulating transcription of the $\operatorname{lu} x S$ gene. The second hypothesis is a possible synergistic anti-biofilm effect between arginine and Agilyte ${ }^{\mathrm{TM}}$ for $P$. aeruginosa biofilms. A study performed demonstrated that arginine can increase the susceptibility of $P$. aeruginosa to two classes of antimicrobials in mature biofilms. ${ }^{32}$ Therefore, the results obtained with PA14 grown in a medium containing arginine could support the possibility of such synergistic effect.

\section{Conclusion}

The ability of bacteria to form biofilms is recognized as important virulence and antimicrobial resistant factors. The results presented here demonstrate that Agilyte ${ }^{\mathrm{TM}}$, at given concentrations and under specific biochemical environments, inhibits biofilms of both grampositive and gram-negative bacteria. The data suggest that Agilyte ${ }^{\mathrm{TM}}$ may inhibit the AI-2 cell signaling mechanism in bacteria. This study did not provide conclusive evidence of a possible synergistic anti-biofouling/antimicrobial effect of Agilyte ${ }^{\mathrm{TM}}$ and Penicillin G. However, given that the study yielded some questionable and variable results, data generated using polystyrene microtiter plates should be evaluated with caution and further studies are required to fully evaluate and validate the spectrum of anti-biofouling properties of this chemical compound. The biochemical environment where clinical bacterial biofilms form is an important factor when designing biofilm assays. Therefore, future in-vitro studies should include accurate and representative models of relevant tissue and medical device surfaces where these microbial communities develop. Consideration should be given to experiments with simulated body fluid (SBF) and simulated 
wound models. Only through such realistic ex-vivo models will one be able to fully explore the effect of anti-biofilm chemicals, such as Agilyte ${ }^{\mathrm{TM}}$, on inhibiting and/or disrupting biofilms of clinically relevant bacteria as well as their potential use as an adjuvant in antimicrobial therapies.

\section{Acknowledgements}

This study was performed as an Applied Research project in Partial Fulfillment of the Requirements for the Doctor of Health Sciences degree from A.T. Still University (Mesa, AR) and approved by Jeffrey L. Alexander, PhD and Helen Ewing, RN, DHSc (A.T. Still University, Mesa, AR) and John Cavanagh, PhD (Department of Molecular and Structural Biochemistry, at North Carolina State University, Raleigh, NC). The Study was supported by Diosynth Biotechnology (Morrisville, NC). I am grateful to Dr. Christian Melander (Department of Chemistry, at North Carolina State University, Raleigh, NC) for his technical support and for generously providing the chemical Agilyte ${ }^{\mathrm{TM}}$ 8000, Luria-Bertani broth with no salt (LBNS), and the bacteria Staphylococcus epidermidis ATCC 29886, methicillin-resistant Staphylococcus aureus (ATCC BAA-44), and Pseudomonas aeruginosa PA14. I am also grateful to Dr. John Cavanagh for his support and guidance as the External Committee Member for my Applied Research Project. Finally, I would like to thank DB Diagnostics (MD, USA) for providing the Luria-Bertani broth used in the studies.

\section{Conflict of interest}

The author declares that there is no conflict of interest.

\section{References}

1. Roberts ME, Stewart PS. Modeling protection from antimicrobial agents in biofilms through the formation of persister cells. Microbiology 2005;151:75-80.

2. Wilson M. Bacterial biofilms and human disease. Science Progress. 2001;84(3):235-254.

3. Demling RH, Waterhouse B. The increasing problem of wound bacterial burden and infection in acute and chronic soft-tissue wound caused by methicillin-resistant Staphylococcus aureus. J Burns Wounds. 2007;7:e8.

4. Schachter B. Slimy business: The biotechnology of biofilms. Nature Biotechnology. 2003;21:361-365.

5. Dolan RM, Costerton JW. Biofilms: Survival mechanisms of clinically relevant microorganisms. Clin Microbiol Rev. 2002;15(2):167-193.

6. Davey ME. O Toole GA. Microbial biofilms: From ecology to molecular genetics. Microbiol Mol Biol Rev. 2000;64(4):847-867.

7. Costerton W, Veeh R, Shirtliff M, et al. The application of biofilm science to the study and control of chronic bacterial infections. J Clin Invest. 2003;112(10):1466-1477.

8. James GA, Swogger E, Wolcott R, et al. Biofilms in chronic wounds. Wound Repair Regen. 2008;16(1):37-44.

9. Dror N, Mandel M, Hazan Z, et al. Advances in microbial biofilm prevention on indwelling medical devices with emphasis on usage of acoustic energy. Sensors(Basel). 2009;9(4):2538-2554.

10. Danese PN. Antibiofilm approaches: Prevention of catheter colonization. Chem Biol. 2002;9(8):873-880.

11. Assman M, Lichte E, Pawlik J, et al. Chemical defenses of the Caribbean sponges Agelaswiedenmayeri and Agelasconifera. Marine Ecology Progress Series. 2000;207:255-262.

12. Huigens RW, Gambino C, Moeller PD, et al. Control of bacterial biofilms with marine alkaloid derivatives. Molecular bio Systems. 2008;4(6):614-621.

13. Clontz, L. Biofilms. In Clontz (Ed.), Microbial limit and bioburden tests: Validation approaches and global requirements. Boca Raton: $C R C$ Press. 2008;263-297.

14. Ren D, Zuo R, Gonzales Barrios AF, et al. Differential gene expression for investigation of Escherichia coli biofilm inhibition by plant extract ursolic acid. Applied and Environmental Microbiology. 2005;71(7):4022-4034

15. Pitts B, Hamilton A, Zelver N, et al. A microtiter-plate screening method for biofilm disinfection and removal. $J$ Microbiol Methods. 2003;54(2):269-276.

16. Jesaitis AJ, Franklin MJ, Berglund D, et al. Compromised host defense on Pseudomonas aeruginosa biofilms: Characterization of neutrophil and biofilm interactions. J Immunol. 2003;171(8);4329-4339.

17. Dolan RM. Biofilms and device-associated infections. Emerg Infect Dis. 2001;7(2):277-281.

18. Vuong C, Voyich JM, Fischer ER, et al. Polysaccharide intercellular adhesin (PIA) protects Staphylococcus epidermidis against major components of the human innate immune system. Cell Microbiol. 2004;6(3):269-275.

19. Fux CA, Wilson S, Stoodley P. Detachment characteristics and oxacillin resistance of Staphylococcus aureus biofilm emboli in an in vitro catheter infection model. J Bacteriol. 2004;186(14):4486-4491.

20. Centers for Disease Control and Prevention [CDC]. Staphylococcus aureus with reduced susceptibility to vancomycin. Morbidity and Mortality Weekly Report. 1997;46(33):765-766.

21. Bauernfeind $\mathrm{A}$, Petermüller $\mathrm{C}$. In vitro activity of teichomycin A 2 in comparison with penicillin and vancomycin against gram-positive cocci. European Journal of Clinical Microbiology. 1982;1(5):278-281.

22. Herigstad B, Hamilton M, Heersink J. How to optimize the drop plate method for enumerating bacteria. Journal of Microbiological Methods. 2001;44(2):121-129.

23. Hamilton M, Heersink J, Buckingham Meyer K. Basic biofilm analytical methods. In Hamilton (Ed.), The biofilm laboratory: Step-bystep protocols for experimental design, analysis, and data interpretation (p. 27). Cytergy.com: Cytergy Scientific E-Learning.

24. United States Pharmacopeia [USP 41-NF36]. Chapter 61, Microbiological examination of non-sterile products: Microbial enumeration tests. The United States Pharmacopeial Convention. Rockville: MD

25. Raffa RB, Iannuzzo JR, Levine DR, et al. Bacterial communication ("quorum sensing") via ligands and receptors: A novel pharmacologic target for the design of antibiotic drugs. J Pharmacol Exp Ther. 2005;312(2):417-423.

26. Gonzales JE, Keshavan ND. Messing with bacterial quorum sensing Microbiology and Molecular Biology Reviews. 2006;70(4), 859-875.

27. DeLisa MP, Bentley WE. Bacterial autoinduction: Looking outside the cell for new metabolic engineering targets. Microb Cell Fact. 2002;1(1):5

28. Domka J, Lee J, Wood TK. Ylih (BssR) and YceP(BssS) regulate Escherichia coli K-12 biofilm formation by influencing cell signaling. Applied and Environmental Microbiology. 2006;72(4):2249-2459.

29. Fiegler H, Bassias J, Jankovic I, et al. Identification of a gene in 
Staphylococcus xylosusencoding a novel glucose uptake protein Journal of Bacteriology. 1999;181(16):4929-4936.

30. Xavier KB, Bassler BL. Regulation of uptake and processing of the quorum-sensingautoinducer AI-2 in Escherichia coli. J Bacteriol. 2005;187(1):238-248.

31. Asad S, Opal SM. Bench-to-beside review: Quorum sensing and the role of cell-to-cell communication during invasive bacterial infection. Critical Care. 2008;12:236.

32. Borriello G, Richards L, Ehrlich GD, et al. Arginine or nitrate enhances antibiotic susceptibility of Pseudomonas aeruginosa in biofilms. Antimicrobial Agents and Chemotherapy. 2006;50(1):382-384. 